\title{
Kontribusi Kekuatan Ekstensi Otot Tungkai Dan Kelentukan Pinggul Terhadap Kemampuan Long Passing
}

\author{
Agustiardi $^{1}$, Atradinal ${ }^{2}$, Ridho Bahtra ${ }^{3}$ \\ ${ }^{123}$ Fakultas Ilmu Keolahragaan, Universitas Negeri Padang, Indonesia.
}

E-mail: agustiardi@yahoo.com ${ }^{1}, \underline{\text { atradinal@fik.unp.ac.id }{ }^{3}, \text { ridhobahtra@fik.unp.ac.id }}$

\begin{abstract}
Abstrak
Masalah yang ditemukan bahwa dalam setiap latihan dan setiap turnamen-turnamen para pemain Pulau Tengah melakukan Long Passing tetapi bola tersebut tidak sesuai dengan apa yang diharapkan atau masih dekat, bahkan banyak dari tendangan yang mengenai pemain atau membentur lawan yang berada di depannya. Penelitian ini bertujuan untuk mengetahui Kontribusi kekuatan ekstensi otot tungkai pemain sepakbola Pulau Tengah terhadap kemampuan Long Passing, Mengetahui Kontribusi kelentukan pinggul pemain sepakbola Pulau Tengah terhadap kemampuan Long Passing, Mengetahui Kontribusi kekuatan ekstensi otot tungkai dan kelentukan pinggul terhadap kemampuan Long Passing pemain sepakbola Pulau Tengah.

Data yang diperoleh dalam penelitian ini berasal dari data primer yaitu tes pengukuran yang dilakukan terhadap pemain PS Pulau Tengah yang terpilih menjadi sampel. Hasil tes pengukuran yang dilakukan yaitu, kekuatan ekstensi otot tungkai, tes kelentukan pinggul, dan tes kemampuan Long Passing. Sedang kan data skunder data yang diperoleh dari pengurus PS Pulau Tengah.

Pelaksanaan tes kelentukan pinggul dilakukan dengan sikap berdiri di atas tumpuan alat Legdynamometer. Tes Kelentukan Pinggul pelaksanaannya berdiri di atas alat Flexiometer. Hasil dari Long Passing didapat dari tendangan bola sejauh mungkin dengan meletakan bola yang akan ditendang pada titik yang telah ditentukan pada sepanjang garis batas. Berdasarkan hasil penelitian; Terdapat Kontribusi antara kekuatan ekstensi otot tungkai terhadap kemampuan Long Passing. Artinya, semakin tinggi kekuatan ekstensi otot tungkai yang dimiliki oleh pemain maka akan semakin baik pula hasil dari Long Passing yang dilakukannya.

Hal ini berarti bahwa apabila kekuatan ekstensi otot tungkai ditingkatkan maka kemampuan Long Passing juga akan meningkat. Terdapat Kontribusi antara kelentukan pinggul terhadap kemampuan Long Passing. Artinya, semakin tinggi kelentukan pinggul yang dimiliki oleh pemain maka akan semakin baik pula hasil dari Long Passing yang dilakukannya. Hal ini berarti bahwa apabila kelentukan pinggul ditingkatkan maka kemampuan Long Passing juga akan meningkat. Kekuatan ekstensi otot tungkai dan kelentukan pinggul secara bersama-sama terhadap kemampuan Long Passing memiliki Kontribusi. Berdasarkan koefisien korelasi sebesar 0,060 pada persamaan regresi $\hat{Y}=11.273+0.60 \mathrm{X}_{1}+1.242 \mathrm{X}_{2}$.
\end{abstract}

Kata Kunci: Kekuatan Ekstensi, Otot Tungkai, Kelentukan Pinggul, Long Passing

\begin{abstract}
The problem was found that in every practice and every tournament the Central Island players did Long Passing but the ball did not match what was expected or was still close, even many of the kicks hit the player or hit the opponent in front of him. This study aims to determine the contribution of the strength of the leg muscle extension of Central Island soccer players to the Long Passing ability, to
\end{abstract}




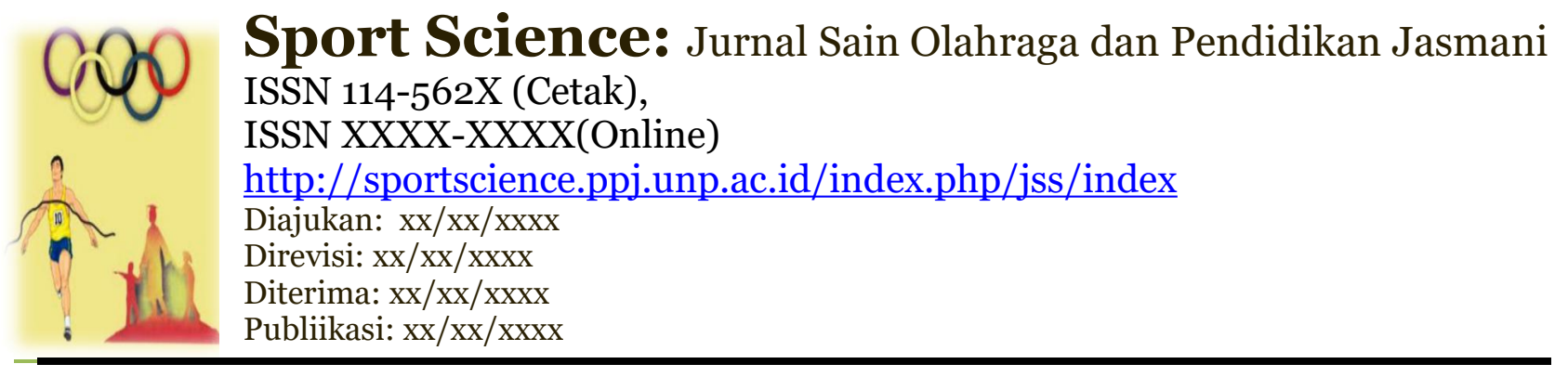

know the contribution of the hip flexion of the Central Island soccer players to the Long Passing ability, to know the contribution of the strength of the leg muscle extension and the hip flexion to the Long Passing ability of the Central Island soccer players.

The data obtained in this study came from primary data, namely measurement tests conducted on PS Pulau Tengah players who were selected as samples. The results of measurement tests carried out namely, strength of leg muscle extension, hip flexion test, and Long Passing ability test. The secondary data was obtained from the Central Island Study Program.

The hip flexion test is performed with a standing stance on the peddynamometer pedestal. The Hip Determination Test stands on a Flexiometer. The result of Long Passing is obtained from the ball kick as far as possible by placing the ball to be kicked at a predetermined point along the boundary line. Based on research results; There is a contribution between the strength of leg muscle extension to the ability of Long Passing. That is, the higher the leg muscle strength extension owned by the player, the better the results of the Long Passing he does.

This means that if the strength of leg muscle extension is increased, the ability of Long Passing will also increase. There is a contribution between hip flexibility to the ability of Long Passing. That is, the higher the hip flexion owned by the player, the better the results of the Long Passing he does. This means that if the flexibility of the hips is increased the ability of the Long Passing will also increase. The strength of leg muscle extension and hip flexion together to the ability of Long Passing have contributed. Based on the correlation coefficient of 0.060 in the regression equation $\hat{Y}=11,273+$ $0.60 X 1+1,242 X 2$.

Keywords: Strength of Extensions, Leg Muscles, Hip Flexion, Long Passing

\section{PENDAHULUAN}

Dalam sepakbola kecepatan sangat tergantung dari kekuatan, karena tanpa kekuatan, kecepatan tidak dapat dikembangkan. Daya tahan adalah kemampuan mengatasi kelelahan. Dalam sepakbola daya tahan merupakan faktor penting karena dalam waktu 2 X45 menit seorang pemain harus bisa bertahan mengontrol fisiknya. Kelentukan merupakan kemampuan pergelangan/persendian untuk dapat melakukan gerakan-gerakan ke semua arah secara optimal. Asnaldi (2019:) "Aktifitas seseorang bisa dilakukan dengan baik jika orang tersebut memiliki tingkat konsentrasi yang tinggi. Karena dalam kehidupan ini berbagai aktifitas yang harus dilakukan sangat kompleks, begitupun dalam aktifitas olahraga".

Sedangkan teknik merupakan segala tindakan yang diperlukan dalam melakukan sesuatu dalam sepakbola. Teknik ada dua bagian yakni teknik dengan bola dan tanpa bola. Teknik dengan bola seperti menendang bola, menahan bola, mengontrol bola, mengiring bola, menyundul bola, melempar bola, dan menepis bola bagi penjaga gawang. Teknik tanpa bola di antaranya terdiri dari: lari, lompat, gerak tipu dan lain-lain. Taktik dalam sepakbola adalah siasat dalam bermain sepakbola baik itu taktik bertahan dan taktik menyerang bagaimana team tersebut bisa bertahan dengan baik dan menyerang dengan baik Darwis dalam Mulian(2019).

Mental merupakan keadaan bathin dalam sepakbola mental juga mendukug agar seseorang atau klub bisa bermain dengan baik dan sesuai dengan apa yang diharapkan seperti: sportivitas, emosional, disiplin, konsentrasi, rasa percaya diri, tanggung jawab, mental sebelum pertandingan, saat pertandingan, sesudah pertandingan dan lain-lain. Faktor eksternal yang mempengaruhi prestasi adalah faktor yang berasal dari luar tubuh di antaranya adalah: sarana dan prasarana, pelatih dan lainlain.

Sarana dan prasarana yang dibutuhkan dalam sepakbola di antaranya adalah: lapangan sepakbola, bola, kostum, dan lain-lain, menyangkut pelatih yang perlu diperhatikan di antaranya adalah: pendidikan pelatih, bagaimana pengetahuan pelatih terhadap sepakbola, bagaimana program 
latihan yang dilakukan pelatih dalam melaksanakan latihan, bagaimana pelatih memberikan semangat terhadap atletnya, loyalitas pelatih terhadap sepakbola tersebut dan lain-lain. jelas bahwa faktor internal dan faktor eksternal sangat berpengaruh sekali dalam pencapaian prestasi olahraga khususnya dalam olahraga sepakbola, jika salah satu dari faktor tersebut belum berjalan dengan baik maka atlet tersebut tidak akan meraih kesuksesan, dan tidak akan sesuai dengan apa yang diharapkan.

Tendangan jarak jauh (Long Paassing) adalah: Memindahkan bola dari suatu tempat ke tempat lain dengan menggunakan kaki atau bagian kaki, baik kaki bagian dalam, kura-kura kaki bagian dalam, kura-kura kaki bagian luar, ujung kaki, dengan keadaan bola diam, bola bergerak atau menggelinding dan bola melayang. Keterampilan menendang bola sangatlah diperlukan oleh seseorang dalam keberhasilan bermain bola, seperti mengadakan serangan balik, mencetak gol, mengoper bola ke kawan, melakukan tendangan hukuman, tendangan bebas dan sudut dan tendangan gawang, jadi tendangan merupakan salah satu prasyarat agar seseorang bisa bermain sepakbola dengan baik.

Jelas bahwa Long Passing merupakan faktor yang sangat penting dalam sepakbola tanpa adanya Long Passing pemain sepakbola tidak akan mudah melewati pemain yang berada di depannya dan tanpa adanya Long Passing tendangan gawang akan mudah di dapat atau di raih oleh pemain lawan ini bisa mengakibatkan kebobolan pada gawang sendiri maka tidak sesuai dengan prinsip sepakbola yakni memasukan bola kegawang lawan sebanyak mungkin dan mempertahankan gawang sendiri dari kebobolan sedikit mungkin. Seiring dengan itu semakin bagus Long Passing maka semakin bagus pula permainan sebuah team bahkan semakin bagus atlet itu bermain.

Berdasarkan pengamatan peneliti di lapangan, dan wawancara peneliti dengan pelatih sekaligus guru Penjas di SMA 1 Pulau Tengah bahwa kemampuan Long Passing di Team PS Pulau Tengah masih jauh dari apa yang diharapkan. Hal ini terbukti dalam setiap latihan dan setiap turnamenturnamen para pemain Pulau Tengah melakukan Long Passing tetapi bola tersebut tidak sesuai dengan apa yang diharapkan atau masih dekat, bahkan banyak dari tendangan yang mengenai pemain atau membentur lawan yang berada di depannya. Oleh karena itu perlu dilakukan penelitian tentang tendangan jarak jauh (Long Passing) dan faktor-faktor yang berkaitan dengan tendangan tersebut. Sehingga dari penelitian ini bisa dihasilkan suatu kesimpulan yang bisa dijadikan sebagai langkah antisipasi dan koreksi terhadap peningkatan prestasi para pemain Pulau Tengah.

Kekuatan ekstensi otot tungkai merupakan kemampuan mengayun lutut sampai ujung kaki ke depan untuk melakukan Long Passing dalam sepakbola. Tanpa adanya kekuatan ekstensi otot tungkai maka seorang pemain tersebut tidak akan bisa melakukan Long Passing, jelas bahwa kekuatan ekstensi otot tungkai memberi sumbangan terhadap kemampuan Long Passing. Semakin kuat ekstensi otot tungkai yang dilakukan maka semakin kuat tendangan yang dihasilkan. Tenaga yang kuat akan memberikan dorongan yang lebih besar, dorongan yang besar akan memberikan Long Passing yang jauh. Dengan ini dapat diduga bahwa kekuatan ekstensi otot tungkai memberikan Kontribusi terhadap kemampuan Long Passing.

Kelentukan pinggul merupakan kemampuan pergelangan/ persendian pinggul agar dapat melakukan gerakan-gerakan ke semua arah secara optimal. Dalam sepakbola kelentukan pinggul terjadi pada saat mengayun kaki ke belakangtanpa adanya kelentukan pinggul bola yang di tendang tidak akan jauh. Semakin besar sudut yang dilakukan maka semakin keras ayunan yang dihasilkan, semakin keras ayunan yang dihasilkan maka semakin jauh tendangan yang dihasilkan. Dengan ini dapat diduga bahwa kelentukan pinggul memberikan Kontribusi terhadap kemampuan Long Passing.

Dalam sepakbola kekuatan ekstensi otot tungkai dan kelentukan pinggul sangat dibutuhkan untuk melakukan Long Passing. Tanpa adanya kekuatan ekstensi otot tungkai dan kelentukan pinggul maka Long Passing tidak akan sesuai dengan apa yang diharapkan. kekuatan ekstensi otot tungkai dan kelentukan pinggul menjadi faktor utama dalam melakukan Long Passing untuk mencapai tujuan yang diharapkan seperti jauh dan tepat nya tendangan tersebut. Jadi semakin kuat ekstensi otot tungkai dan semakin luas sudut yang dihasilkan maka semakin keras dan jauh tendangan yang dihasilkan atau semakin efektif Long Passing yang dihasilkan. Dengan ini dapat diduga bahwa kekuatan ekstensi otot 


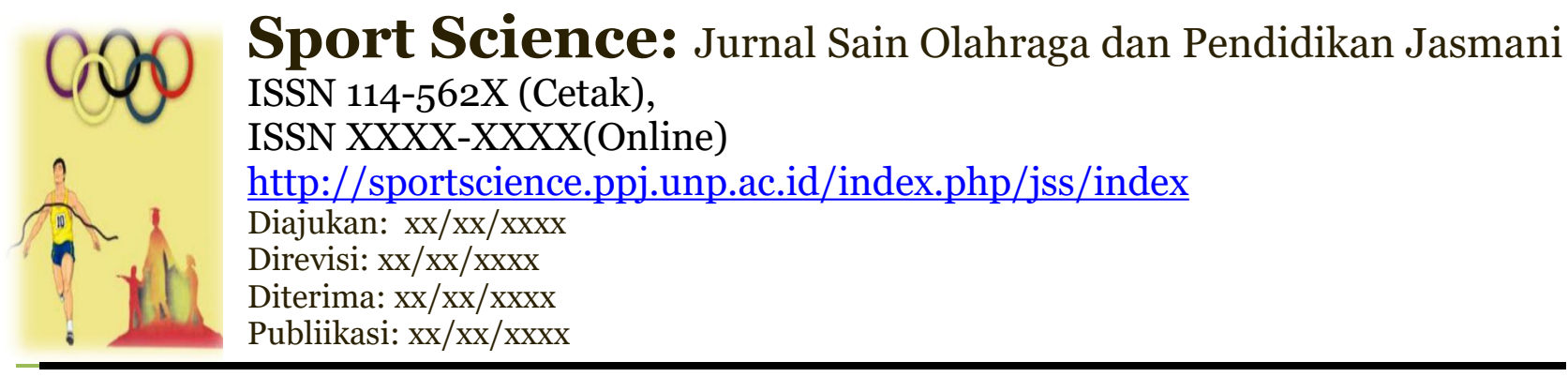

tungkai dan kelentukan pinggul secara bersama memberikan Kontribusi terhadap kemampuan Long Passing.

\section{METODE}

Jenis penelitian ini dalah penelitian Korelasional yang melihat Kontribusi antara variabel bebas terhadap variabel terikat. Variabel bebas adalah kekuatan ekstensi otot tungkai dan Kelentukan pinggul, sedangkan variabel terikat adalah kemampuan Long Passing. Penelitian ini dilaksanakan di Kerinci, tepat nya di SMA Negeri 1 Keliling Danau Pulau Tengah Kabupaten Kerinci Jambi dan waktu yang digunakan adalah dari bulan April sampai bulan Mei tepat nya pada tanggal 25 April sampai tanggal 17 Mei 2008.

Populasi penelitian ini adalah pemain PS Pulau Tengah yang berjumlah 49 orang. Pengambilan sampel ini dilakukan Purposive Sampling, yakni usia di bawah 20 tahun yang teknik nya sudah bagus berjumlah 30 orang.

\section{Teknik Pengumpulan Data}

Data yang diperlukan dalam penelitian ini adalah data yang di peroleh dari tes kekuatan ekstensi otot tungkai, tes kelentukan pinggul dan tes kemampuan Long Passing

a. Alat dan Fasilitas

Diantaranya : bola kaki, lapangan, Legdynamometer, Flexiometer, meteran untuk mengukur jauhnya tendangan, ikat pinggang/tali untuk mengikat alat flexiometer, bangku untuk meletakan alat Flexiometer dan Bubuk kapur untuk membuat garis.

b. Petugas

Dalam penelitian ini peneliti di bantu oleh 5 orang yang masing- masing membantu dalam menyiapkan alat-alat sampai membantu pengambilan data dari tes yang telah di tentukan.

Tabel 1. Daftar Nama yang membantu dalam pengambilan Data

\begin{tabular}{llll}
\hline No & \multicolumn{1}{c}{ Nama } & \multicolumn{1}{c}{ Jabatan } & \multicolumn{1}{c}{ Keterangan } \\
\hline 1 & S. Nugraha Bustami,S.Pd & Pencatat skor & Pelatih guru penjas \\
2 & Sodri S.Pd & Pencatat skor & Pelatih guru \\
3 & Fauzan & Mengukur & Mahasiswa \\
4 & Yose Rizal & Mengukur & Mahasiswa \\
5 & Devi & Mencatat skor & Siswa \\
\hline
\end{tabular}

Data yang diperoleh dalam penelitian ini berasal dari data primer yaitu tes pengukuran yang dilakukan terhadap pemain PS Pulau Tengah yang terpilih menjadi sampel. Hasil tes pengukuran yang dilakukan yaitu, kekuatan ekstensi otot tungkai, tes kelentukan pinggul, dan tes kemampuan Long Passing. Sedang kan data skunder data yang diperoleh dari pengurus PS Pulau Tengah. Data yang diperlukan dalam penelitian ini bersumber dari pemain PS Pulau Tengah, data diambil dengan jalan melakukan tes kekuatan ekstensi otot tungkai, tes kelentukan pinggul, dan tes kemampuan Long Passing.

\section{Instrumen}

\section{Tes Kekuatan Ekstensi Otot Tungkai}

Pelaksanaan tes kelentukan pinggul dilakukan dengan sikap berdiri di atas tumpuan alat Legdynamometer. Kedua tangan memegang bagian tengah tongkat pegangan, punggung dan kedua tangan lurus, sedangkan lutut ditekukkan membuat sudut lebih kurang 120 derajat. Tongkat dipegang berada antara perut dengan paha, digunakan sabuk/ikat pinggang yang bisa mengikat antara pinggang dengan tongkat pegangan dari Legdynamometer. Dengan cara demikian, pelaksanaan dan alat yang digunakan lebih praktis dan efisien di bandingkan dengan alat Leg pres yang memakan waktu lebih lama. Untuk lebih jelasnya dapat dilihat pada Gambar 2 dan 3 di bawah ini : 


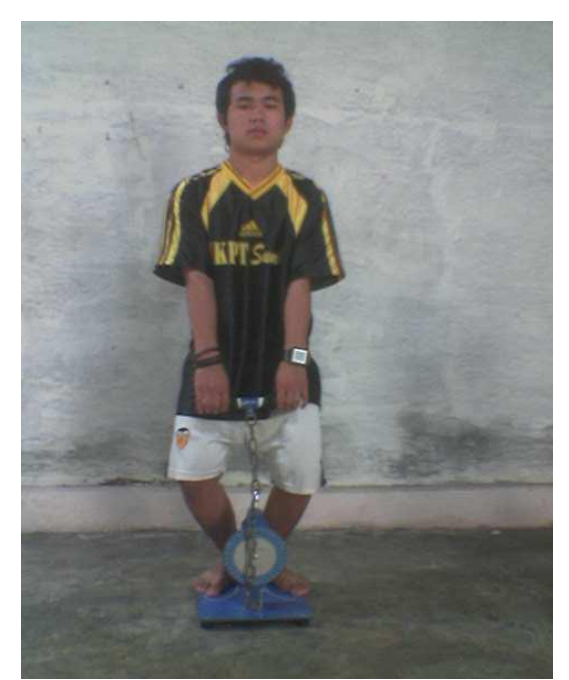

Gambar 2. Teste melakukan gerakan tes

Kekuatan Ekstensi Otot Tungkai

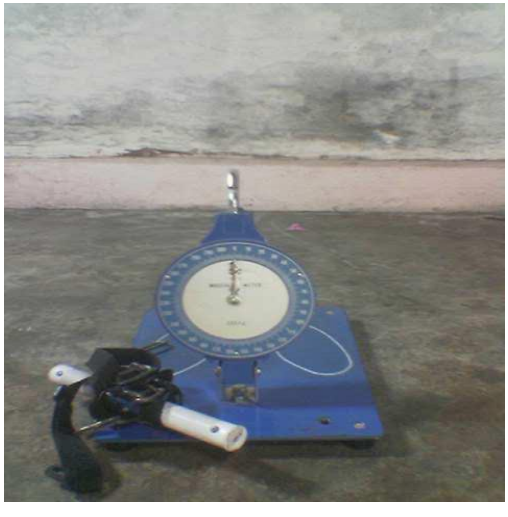

Gambar 3. Alat Legdynamometer

Ket:Pada pelaksanaan ini tangan hanya memegang dan tangan tidak boleh ikut mengangkat agar hasil yang di raih bisa sesuai dengan apa yang diharapakan

\section{Tes Kelentukan Pinggul}

Tes Kelentukan Pinggul pelaksanaannya berdiri di atas alat Flexiometer dan menekan ke bawah salah satu bagian alat ukur tersebut dengan tangan, dengan syarat lutut tetap lurus kemudian sampai jarak menekan terjauh sikap ini di pertahankan beberapa waktu sehingga hasil nya dapat dilihat oleh penguji. Pelaksanaan tes dapat dilihat pada Gambar 4. tes kelentukan pinggul.

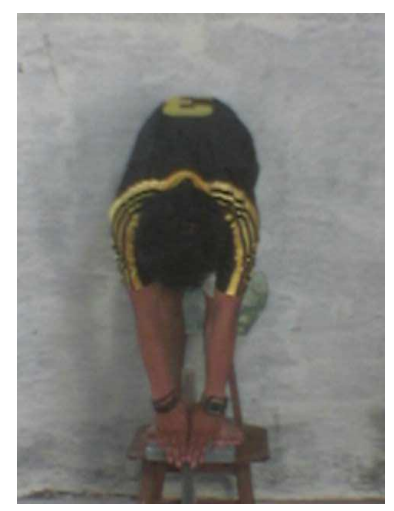

Gambar 4. Teste melakukan gerakan atau tes kelentukan Pinggul

Ket: Dalam pelasanaan gerakan ini kaki tidak boleh di bengkokkan agar hasil yang raih bisa sesuai dengan apa yang diharapkan

\section{Tes Long Passing}

Hasil dari Long Passing didapat dari tendangan bola sejauh mungkin dengan meletakan bola yang akan ditendang pada titik yang telah ditentukan pada sepanjang garis batas. Gerakan pelaksanaan tanpa menunggu aba-aba dari petugas agar si penendang boleh menendang bola. Tendangan di lakukan 2 kali kanan dan dua kali kiri. Hasil yang diambil adalah jumlah jarak dari seluruh tendangan dibagi 4, kelebihan 0,1 meter sampai 0,4 dibulat kan menjadi 0,5 sedangkan kelebihan 0,6 sampai 0,9 dibulatkan menjadi 1 meter.

Alat dan fasilitas yang digunakan adalah bola kaki, meteran tali, bubuk kapur untuk membuat garis batas lapangan dan lapangan yang datar dengan lebar 20 meter panjang 50 meter atau lebih. Mulai dari garis batas 15 meter dari garis batas tendangan dibuat garis batas yang sejajar dengan garis 


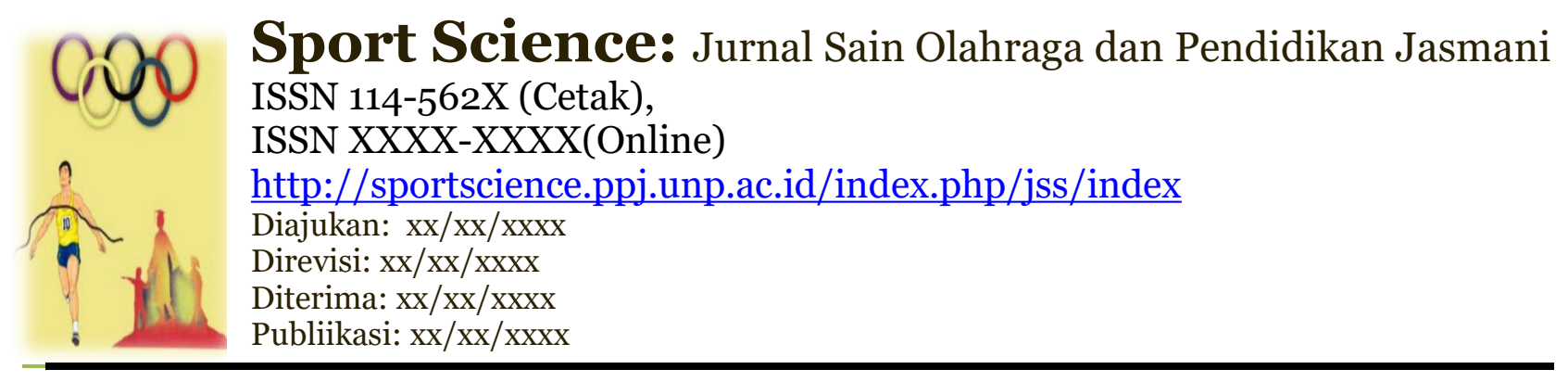

batas berturut-turut dengan jarak 5 meter. Cara pelaksanaan Long Passing dapat dilihat pada Gambar 5 gerakan Long Passing.

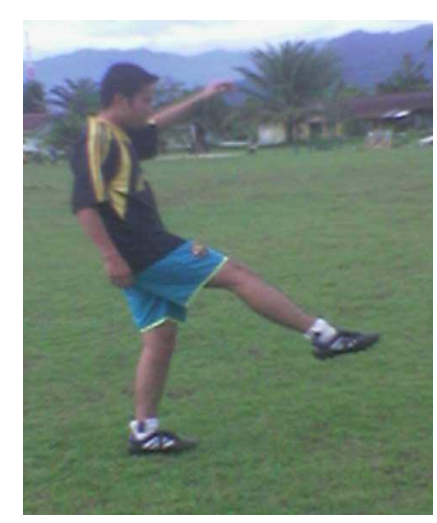

\section{Teknik Analisis Data}

Gambar 5 teste melakukan gerakan Long Passing

Berdasarkan pada Hipotesis yang diajukan analisis data yang dilakukan dengan mengunakan statistik Analisis Regresi Linear sederhana/tunggal dan ganda. Untuk melihat Kontribusi kekuatan ekstensi otot tungkai dan kelentukan pinggul terhadap kemampuan Long Passing. Dengan menggunkan rumus :

$$
\hat{Y}=\mathrm{b}_{\mathrm{o}}+\mathrm{b}_{1} \mathrm{X}_{1}+\mathrm{b}_{2} \mathrm{X}_{2}
$$

Dimana

$\hat{Y} \quad=$ skor yang akan di prediksi berdasarkan skor $\mathrm{X}_{1}$ dan $\mathrm{X}_{2}$

$\mathrm{b}_{\mathrm{o}} \quad=$ Konstanta regresi

$\mathrm{b}_{1} \mathrm{X}_{1}=$ Koefisien regresi $\mathrm{X}_{1}$ terhadap $\mathrm{Y}$

$\mathrm{b}_{2} \mathrm{X}_{2}=$ Koefisien regresi $\mathrm{X}_{2}$ terhadap $\mathrm{Y}$

$b_{o} Y_{1}-b_{1} X_{1}-b_{2} X_{2}$

Untuk Konstanta Regresi (a) menggunakan rumus :

$$
\frac{\left(\sum Y\right)\left(\sum X^{2}\right)-\left(\sum X\right)\left(\sum X Y\right)}{n \sum X^{2}-(X)^{2}}
$$

Sedangkan untuk Koefisien regresi (b) menggunakan rumus :

$$
\frac{n \sum X Y-(X)(Y)}{n \sum X^{2}-(X)^{2}}
$$

Teknik analisa data dan pengujian Hipotesis :

Analisa dalam penelitian menyajikan data melalui tabel Distribusi Frekwensi, (hasil perhitungan tersebut kemudian dideskripsikan dalam daftar Frekwensi masing-masing variabel. Langkah- langkah yang ditempuh sebagai berikut; menghitung nilai rata-rata, Stnandar deviasi. Pengujian terhadap Hipotesis pertama dan kedua menggunakan teknik analisis Regresi dan korelasi sederhana, sedangkan untuk menguji Hipotesis ketiga digunakan teknik analisis regresi dan korelasi ganda yang dilakukan 
dengan menghitung koefesien korelasi. Sebelumnya dilakukan uji persyaratan analisis, yaitu uji Normalitas data dengan Kriteria pengujian pada $\alpha=0,05$.

\section{HASIL DAN PEMBAHASAN \\ Hasil Penelitian}

Data penelitian ini terdiri dari: kemampuan Long Passing $(\mathrm{Y})$ sebagai variabel terikat, Kekuatan ekstensi otot tungkai $\left(\mathrm{X}_{1}\right)$ dan kelentukan pinggul $\left(\mathrm{X}_{2}\right)$ sebagai variabel bebas. Berdasarkan data penelitian untuk skor kemampuan Long Passing diperoleh skor terendah 19,50 dan skor tertinggi 35,50. Dari analisis data diketahui skor rata-rata sebesar 26,45, Standar Deviasi 4.84. Dengan menggunakan Distribusi Frekuensi sebagaimana terlihat pada Tabel 1 berikut:

Tabel 2. Distribusi Frekuensi Kemampuan Long Passing

\begin{tabular}{ccc}
\hline Y & Frekuensi Absolut & Frekuensi Relatif \\
\hline $19.50-23.49$ & 11 & $37 \%$ \\
$23.50-27.49$ & 5 & $17 \%$ \\
$27.50-31.49$ & 9 & $30 \%$ \\
$31.50-35.49$ & 4 & $13 \%$ \\
$35.50-39.49$ & 1 & $3 \%$ \\
Jumlah & 30 & $100 \%$ \\
\hline
\end{tabular}

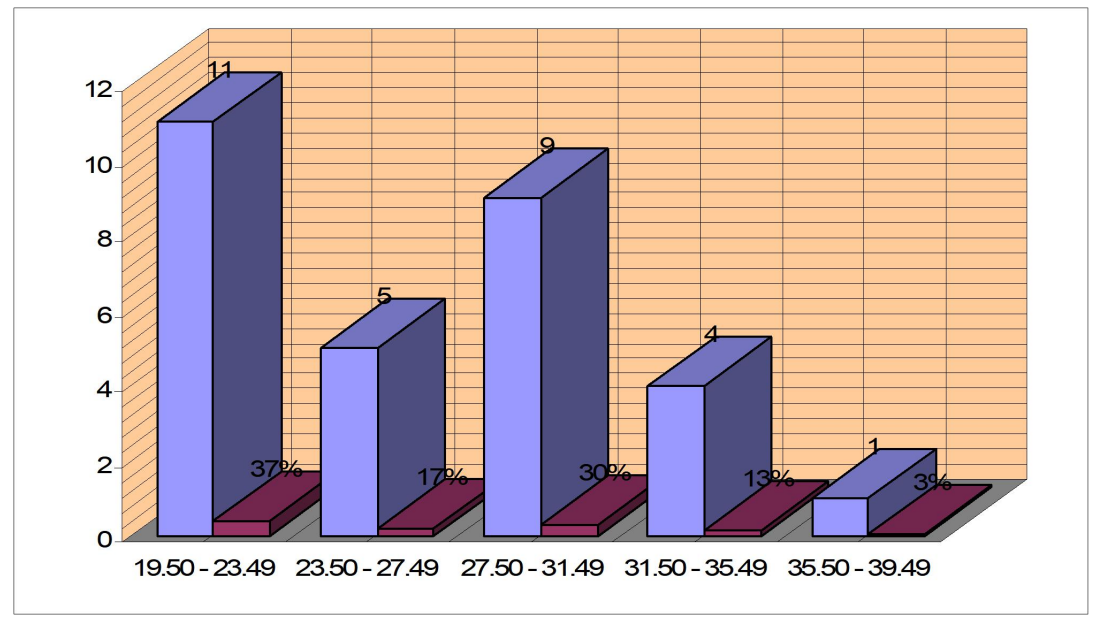

Gambar 6. Grafik Histogram Kemampuan Long Passing

\section{Kekuatan Kekuatan Ekstensi Otot Tungkai $\left(\mathrm{X}_{1}\right)$}

Berdasarkan data penelitian untuk skor kekuatan ekstensi otot tungkai diperoleh skor terendah 19 dan skor tertinggi 45. Dari analisis data diketahui skor rata-rata sebesar 28.13, Standar Deviasi 7.22. Dengan menggunakan distribusi Frekuensi sebagaimana tampak pada Tabel 2 berikut:

Tabel 3. Distribusi Frekuensi Kekuatan Ekstensi Otot Tungkai

\begin{tabular}{ccc}
\hline X1 & Frekuensi Absolut & Frekuensi Relatif \\
\hline $19-24$ & 11 & $37 \%$ \\
$25-30$ & 8 & $27 \%$ \\
$31-36$ & 8 & $27 \%$ \\
$37-42$ & 2 & $7 \%$ \\
$43-48$ & 1 & $3 \%$ \\
Jumlah & 30 & $100 \%$ \\
\hline
\end{tabular}



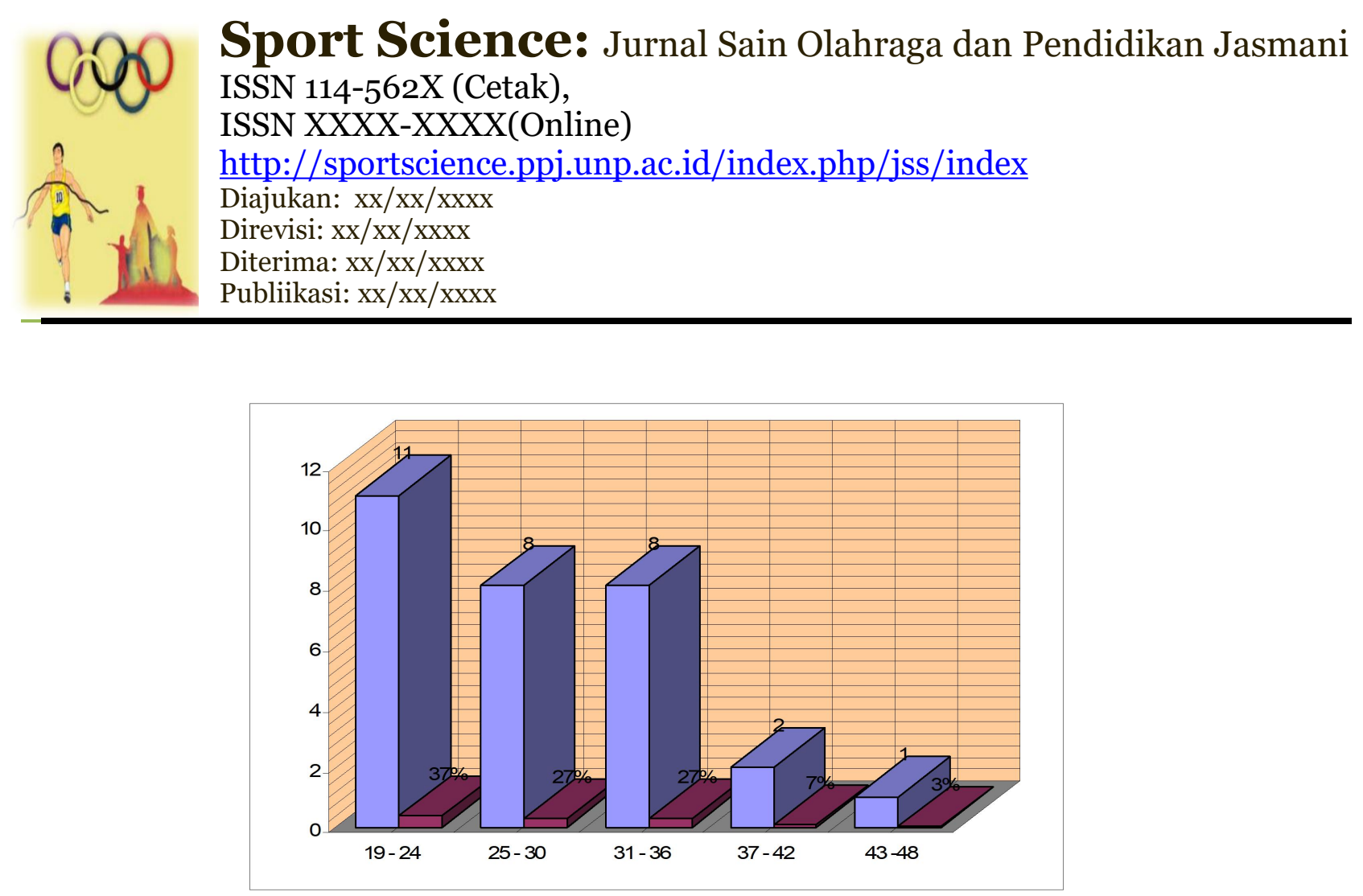

\section{Kelentukan Pinggul $\left(\mathbf{X}_{2}\right)$}

Gambar 7. Grafik Histogram Kekuatan Ekstensi Otot Tungkai $\left(\mathrm{X}_{1}\right)$

Berdasarkan data penelitian untuk skor kelentukan pinggul diperoleh 15. Dari analisis data diketahui skor terendah 7 dan skor tertinggi 15 dan rata-rata sebesar 10,87, Standar Deviasi 2.19. Dengan menggunakan Distribusi Frekuensi sebagaimana tampak pada Tabel 3 berikut:

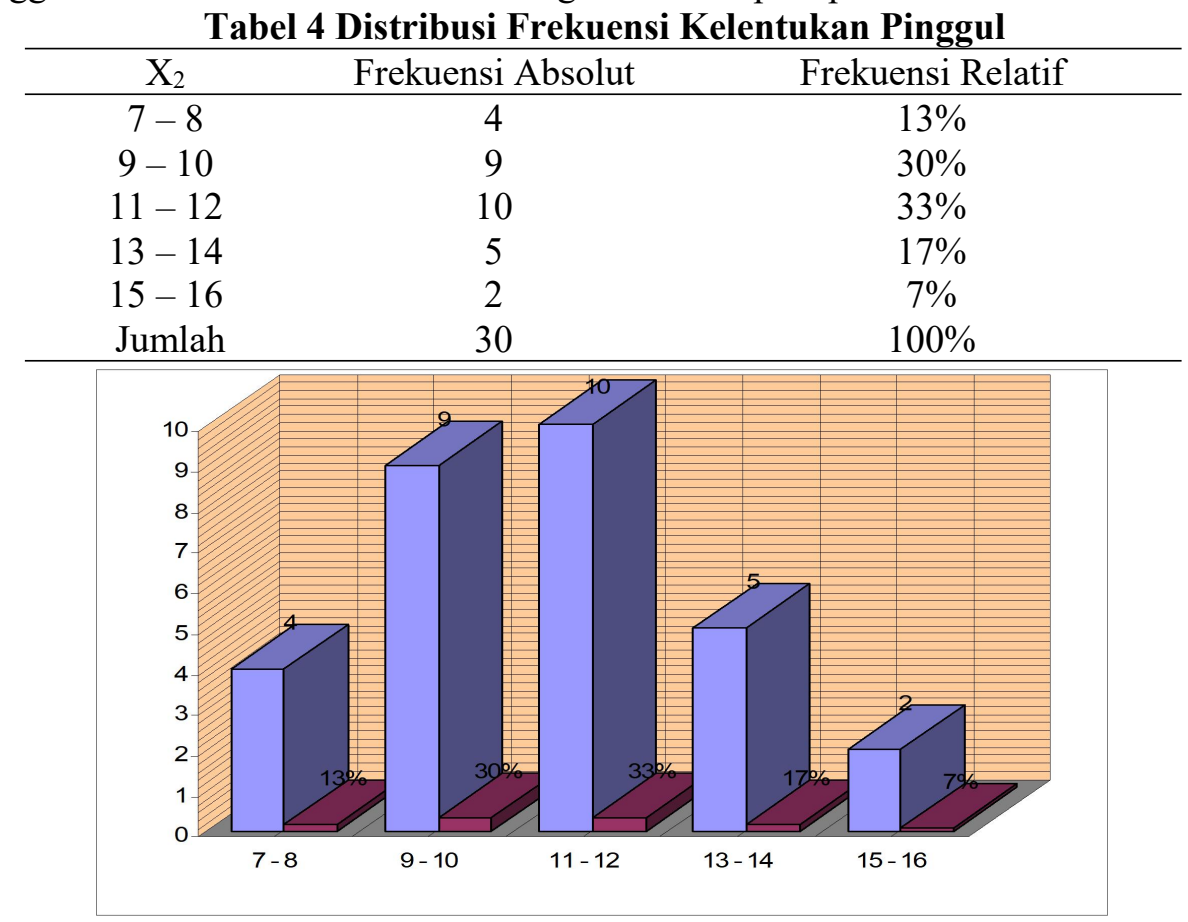

Gambar 8. Grafik Histogram kelentukan Pinggul $\left(\mathrm{X}_{2}\right)$

\section{Uji Persyaratan Analisis}

Uji Hipotesis penelitian dilakukan dengan analisis regresi. analisis regsresi dapat dilakukan bila data yang dianalisis memenuhi beberapa persyaratan, yaitu: data berdistribusi Normal. Untuk melihat apakah persyaratan tersebut dapat terpenuhi atau tidak, maka perlu dilakukan uji persyaratan analisis. 
Dari hasil pengolahan data melalui Uji Normalitas diperoleh angka Normalitas Distribusi data seperti pada Tabel 5

Tabel 5. hasil Uji Normalitas Data

\begin{tabular}{lccc}
\hline \multicolumn{1}{c}{ Varibel } & Lo & Lt & Ket \\
\hline Kekuatan Ekstensi Otot Tungkai & 0.137 & 0.161 & Normal \\
Kelentukan Pinggul & 0.135 & 0.161 & Normal \\
Kemampuan Long Passing & 0.126 & 0.161 & Normal
\end{tabular}

Berdasarkan Tabel 5 di atas dapat dilihat bahwa Lo dari Kekuatan Ekstensi otot tungkai sebesar 0.137 dan Lt 0.161. Sedangkan Lo dari Kelentukan Pinggul sebesar 0.135 dan Lt 0.161, dan Lo dari Long Passing sebesar 1.26 dan Lt sebesar 0.161. Jelas Lo dari semua variabel lebih kecil dari Lt maka dapat disimpulkan bahwa data tersebut Normal. Berikut akan disajikan hasil penguian Hipotesis penelitian yang akan diajukan.

Hipotesis kerja yang diajukan adalah terdapat Kontribusi yang signifikan dan positif antara kekuatan ekstensi otot tungkai terhadap kemampuan Long Passing. Dari hasil pengolahan data diperoleh Kontribusi kekuatan ekstensi otot tungkai terhadap kemampuan Long Passing sebesar 7,29\%. Hasil regresi Liniear sederhana terhadap data penelitian, hasil analisis varian antara kekuatan ekstensi otot tungkai terhadap kemampuan Long Passing diperoleh seperti Tabel 6 berikut:

Daftar ANAVA Regresi Linear Sederhana Kontribusi Kekuatan Ekstensi Otot Tungkai Terhadap Kemampuan Long Passing $\hat{\mathbf{Y}} 21.273=+0.190 \mathrm{X}$

\begin{tabular}{|c|c|c|c|c|c|c|}
\hline $\begin{array}{c}\text { Sumber } \\
\text { Variasi }\end{array}$ & Dk & JK & $\mathrm{KT}$ & $\mathrm{Fh}$ & $\begin{array}{l}\text { Ft } \alpha \\
=0.05\end{array}$ & Kesimpulan \\
\hline Total & 30 & 21668.25 & - & - & - & - \\
\hline Koefisien (a) & 1 & 21.273 & - & - & - & - \\
\hline Regresi (b/a) & 1 & 52.905 & 52.905 & \multirow{2}{*}{68.61} & \multirow{2}{*}{4.20} & \multirow{2}{*}{$\begin{array}{l}\text { Regresi } \\
\text { signifikan } \\
\text { (berarti) }\end{array}$} \\
\hline Sisa & 28 & 21.59 & 0.771216857 & & & \\
\hline Tuna Cocok & 15 & 21.3400 & 1.422666667 & \multirow{2}{*}{0.72} & \multirow{2}{*}{2.55} & Regresi \\
\hline Galat & 13 & 253.39 & 19.49153846 & & & Linear \\
\hline
\end{tabular}

Berdasarkan analisis varian regresi memberikan gambaran bahwa $\mathrm{F}$ hitung yang didapat adalah sebesar 68.61 lebih besar dari $\mathrm{F}_{\text {tabel }}$ 4.20. Dengan demikian dapat disimpulkan bahwa regresi antara kekuatan ekstensi otot tungkai terhadap kemampuan Long Passing mempunyai Kontribusi yang bersifat signifikan (berarti). Sedangkan untuk uji Linearitasnya di peroleh $F_{\text {hitung }} 0.72$ lebih besar dari $\mathrm{F}$ tabel yakni 2.55. Dengan demikian dapat di simpulkan bahwa regresi antara kekuatan ekstensi otot tungkai terhadap kemampuan Long Passing mempunyai Kontribusi yang bersifat Linear.

Dari hasil analisis regresi didapat nilai konstanta regresi $(a)=21.27$ dan nilai koefisien regresinya $=0.18$ dari hasil tersebut diperoleh persamaan regresi $\hat{Y}=21.27+0.18 \mathrm{X}_{1}$. Hal ini bearti, jika terjadi penambahan satu unit skor $\mathrm{X}$, maka secara bersamaan akan terjadi penambahan skor $\mathrm{X}$ sebesar 0.18 unit penambahan skor $\mathrm{X}_{1}$.

Hipotesis kerja yang diajukan adalah terdapat Kontribusi yang signifikan dan positif antara kelentukan pinggul terhadap kemampuan Long Passing. Dari hasil pengolahan data diperoleh Kontribusi kelentukan pinggul terhadap kemampuan Long Passing sebesar 34,81\%. Hasil regresi liniear sederhana terhadap data penelitian, hasil Analisis varian antara kelentukan pinggul terhadap kemampuan Long Passing diperoleh seperti Tabel 7. berikut: 


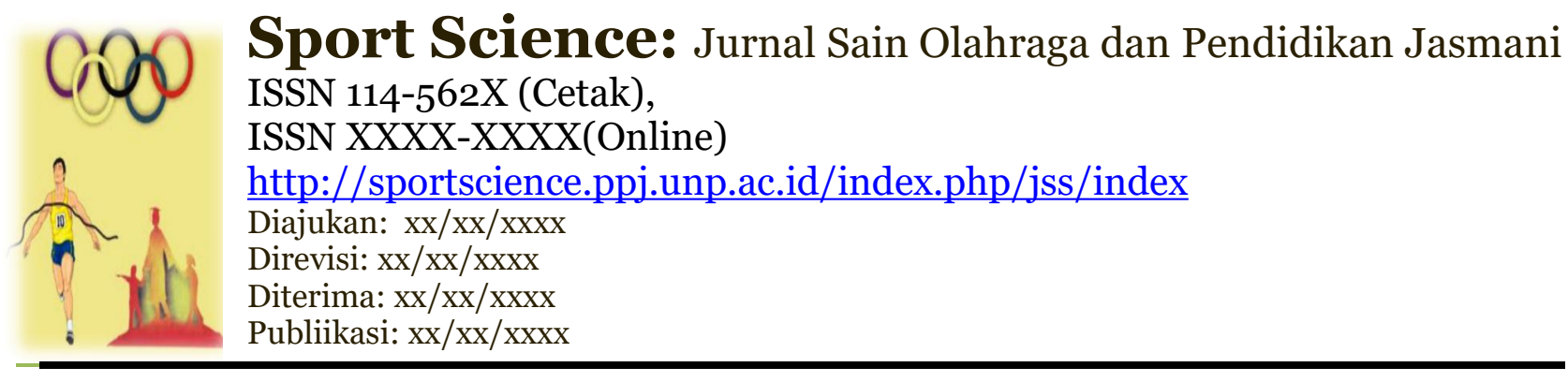

Daftar ANAVA Regresi Linear Sederhana Kontribusi Kelentukan Pinggul Terhadap Kemampuan Long Passing $\hat{\mathbf{Y}}=12.133+1.276 \mathrm{X}_{1}$

\begin{tabular}{lcccccc}
\hline \multicolumn{1}{c}{$\begin{array}{c}\text { Sumber } \\
\text { Variasi }\end{array}$} & Dk & JK & KT & Fh & $\begin{array}{c}\text { Ft } \alpha \\
=0.05\end{array}$ & Kesimpulan \\
\hline Total & 30 & 21668.25 & - & - & - & - \\
Koefisien (a) & 1 & 12.55 & - & - & - & - \\
Regresi (b/a) & 1 & 11.224 & 11.224 & & & $\begin{array}{l}\text { Regresi } \\
\text { signifikan } \\
\text { (berarti) }\end{array}$ \\
Sisa & 28 & 10.431 & 0.372535714 & & & $\begin{array}{l}\text { Regresi } \\
\text { Linear }\end{array}$ \\
Tuna Cocok & 7 & 9.3050 & 1.329285714 & $\mathbf{4 . 2 0}$ & $\mathbf{2 . 5 5}$ & \\
Galat & 21 & 1126.36 & 53.63619048 & & & (.027
\end{tabular}

Selanjutnya analisis varian regresi memberikan gambaran bahwa $\mathrm{F}$ hitung yang didapat adalah sebesar 30.17 lebih besar dari $\mathrm{F}_{\text {tabel }}$ 4.20. Dengan demikian dapat disimpulkan bahwa regresi antara kelentukan pinggul terhadap kemampuan Long Passing mempunyai Kontribusi yang bersifat berarti.Sedangkan untuk uji Linearitas diperoleh $\mathrm{F}$ hitung sebesar 0.0247 lebih kecil dari $\mathrm{F}$ tabel 2.55 . Dengan demikian dapat disimpulkan bahwa regresi antara kelentukan pinggul terhadap kemampuan Long Paasing mempunyai Kontribusi yang bersifat Linear.

Dari hasil analisis regresi didapat nilai konstanta regresi (a) $=12,25$ dan nilai koefisien regresinya $=1,31$. dari hasil tersebut diperoleh persamaan regresi $\hat{Y}=12.25+1.31 \mathrm{X}_{2}$. Hal ini berarti, jika terjadi penambahan satu unit skor $\mathrm{X}$, maka secara bersamaan akan terjadi penambahan skor $\mathrm{X}$ sebesar 1.131 unit penambahan skor $\mathrm{X}_{2}$.

Hipotesis kerja yang diajukan adalah terdapat Kontribusi yang signifikan dan positif antara kekuatan ekstensi otot tungkai dan kelentukan Pinggul terhadap kemampuan Long Passing. Berdasarkan hasil analisis regresi didapat nilai konstanta regresi (a) $=11.273$ dan nilai koefisien regresinya $=0.060$ dan 1.242. Dari hasil tersebut diperoleh persamaan regresi $\hat{Y}=11.273+0.060 \mathrm{X}_{1}+$ $1.242 \mathrm{X}_{2}$. Hal ini berarti, jika terjadi penambahan satu unit skor $\mathrm{X}$, maka secara bersamaan akan terjadi penambahan skor X sebesar 0.18 dan 1.242 unit penambahan skor X, dan dapat di lihat pada Tabel 8 berikut:

Daftar ANAVA Regresi Linear Sederhana Kontribusi kekuatan Ekstensi Otot Tungkai dan Kelentukan Pinggul Terhadap Kemampuan Long Passing

\begin{tabular}{|c|c|c|c|c|c|c|}
\hline Sumber Variasi & Dk & JK & KT & $\mathrm{Fh}$ & $\begin{array}{l}\text { Ft } \alpha \\
=0.05\end{array}$ & Kesimpulan \\
\hline Total & 30 & 21668.25 & - & - & - & \\
\hline Koefisien $\left(b_{0}\right)$ & 3 & 11.273 & - & - & - & \\
\hline Regresi (b/a) & 2 & 242.48 & 212.24 & \multirow{2}{*}{7.49} & \multirow{2}{*}{3.35} & \multirow{2}{*}{$\begin{array}{l}\text { Regresi } \\
\text { (berarti) }\end{array}$} \\
\hline Sisa & 28 & 437.33 & 15.619 & & & \\
\hline
\end{tabular}

Selanjutnya analisis varian regresi memberikan gambaran bahwa $\mathrm{F}$ hitung yang didapat adalah sebesar 7.496 lebih besar dari $\mathrm{F}_{\text {tabel }}$ 3.35. Dengan demikian dapat disimpulkan bahwa regresi antara kekuatan ekstensi otot tungkai dan kelentukan pinggul terhadap kemampuan Long Passing mempunyai Kontribusi yang bersifat linear. 


\section{Pembahasan}

Kemampuan dalam melakukan Long Passing hanya dapat diperoleh melalui latihan-latihan yang teratur dan terpogram serta terencana sehingga Long Passing yang diharapkan dapat dicapai dengan maksimal. Dalam hal ini kekuatan ekstensi otot tungkai juga mempunyai peranan yang sangat besar disamping kemampuan fisik lainnya. Beberapa usaha lain yang dapat ditempuh untuk meningkatkan kemampuan Long Passing antara lain dengan melakukan latihan dengan baik dengan pengulangan yang lebih banyak.

Dalam penelitian ini sebagai pokok kajian adalah Kontribusi antara kekuatan ekstensi otot tungkai terhadap kemampuan Long Passing memberikan Kontribusi sebesar 7,29\%. Hasil dari penelitian ini akan berpengaruh terhadap pemain yang dilatih, dimana hasil yang dicapai dalam Long Passing juga dipengaruhi oleh kekuatan ekstensi otot tungkai. Apabila kekuatan ekstensi otot tungkai ditingkatkan maka kemampuan Long Pasing juga akan meningkat, sebaliknya apabila kekuatan ekstensi otot tungkai turun maka hasil dari Long Passing juga akan menurun. Jadi dalam melakukan Long Passing kekuatan ekstensi otot tungkai sangat berpengaruh terhadap hasil dari Long Passing yang dilakukan oleh seorang pemain sepakbola.

Kemudian Kontribusi antara kelentukan pinggul terhadap kemampuan Long Passing memberikan Kontribusi sebesar $34.81 \%$. Sehingga kelentukan pinggul juga sangat berpengaruh dalam melakukan Long Passing. Apabila semakin bagus kelentukan pinggul seorang pemain maka akan semakin mudah dalam melakukan berbagai macam gerakan Long Passing. Dalam sebuah permainan sepakbola kesempatan Long Passing sangat terbatas oleh waktu, ruang yang sempit, penjagaan dari pihak lawan dan kondisi tubuh yang diganggu oleh lawan, pemain tetap juga melakukan gerakan tendangan dengan tingkat kelentukan yang bagus tentu akan dapat melakukan tendangan sesuai yang diharapkan.

Hal ini sejalan dengan pendapat Arsil (1999:58) bahwa kelentukan adalah salah satu unsur kondisi fisik yang menentukan dalam mempelajari keterampilan-keterampilan gerakan, mencegah cedera, mengembangkan kemampuan kekuatan, kecepatan, dayatahan, dan koordinasi. Dan hubungan antara kekuatan ekstensi otot tungkai dan kelentukan pinggul terhadap kemampuan Long Passing memberikan Kontribusi sebesar 42,10\% terhadap kemampuan Long Passing 57,9\% juga dipengaruhi oleh faktor lain yang tidak diteliti dalam penelitian ini

\section{KESIMPULAN}

Berdasarkan hasil penelitian yang dapat; Terdapat Kontribusi antara kekuatan ekstensi otot tungkai terhadap kemampuan Long Passing. Artinya, semakin tinggi kekuatan ekstensi otot tungkai yang dimiliki oleh pemain maka akan semakin baik pula hasil dari Long Passing yang dilakukannya. Hal ini berarti bahwa apabila kekuatan ekstensi otot tungkai ditingkatkan maka kemampuan Long Passing juga akan meningkat; Terdapat Kontribusi antara kelentukan pinggul terhadap kemampuan Long Passing. Artinya, semakin tinggi kelentukan pinggul yang dimiliki oleh pemain maka akan semakin baik pula hasil dari Long Passing yang dilakukannya.

Hal ini berarti bahwa apabila kelentukan pinggul ditingkatkan maka kemampuan Long Passing juga akan meningkat; dan Kekuatan ekstensi otot tungkai dan kelentukan pinggul secara bersama-sama terhadap kemampuan Long Passing memiliki Kontribusi. Berdasarkan koefisien korelasi sebesar 0,060 pada persamaan regresi $\hat{\mathrm{Y}}=11.273+0.60 \mathrm{X}_{1}+1.242 \mathrm{X}_{2}$. Penelitian yang telah dikemukan beberapa saran seperti; Para pemain hendaknya meningkatkan kekuatan ekstensi otot tungkai agar dalam melakukan Long Passing dapat mencapai hasil yang maksimal,

Pada para pemain hendaknya meningkatkan kelentukan pinggul agar dapat mempermudah melakukan Long Passing sehingga hasil yang dicapai juga maksimal, Perlu diadakan penelitian lanjutan yang lebih khusus dan detail terhadap indokator-indikator lain dan perlu mengkaji lebih lanjut faktor-faktor lain yang turut mempengaruhi kemampuan Long Passing, Pada para pelatih hendaklah mengetahui apa saja faktor-faktor yang mempengaruhi kemampuan dari Long Passing 


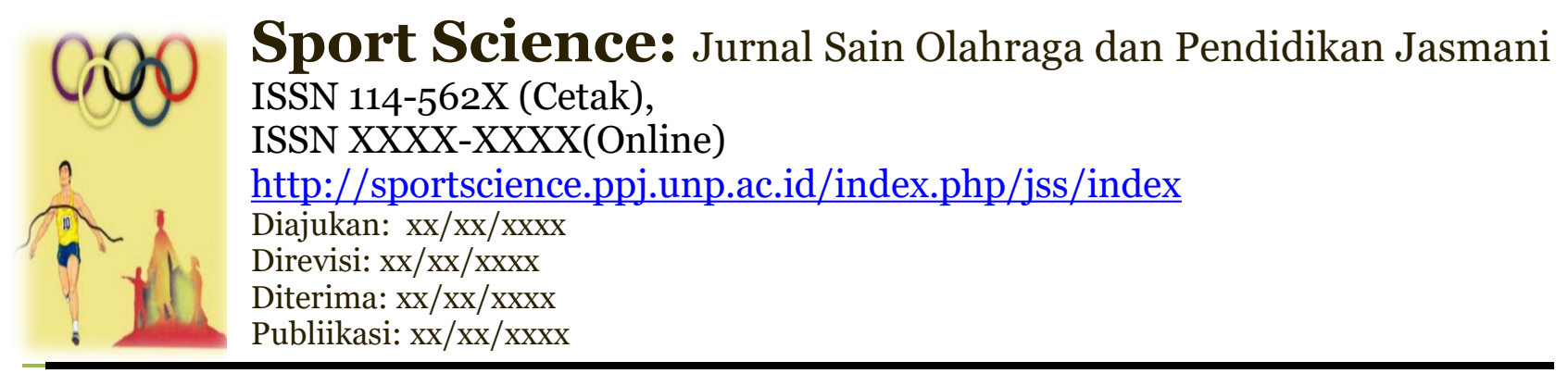

\section{DAFTAR RUJUKAN}

AIP. Syarifuddin (1992). Ateltik. Depdikbud. Dikti

Ambayar (1990) Hubungan Hasil Belajar Mata Kuliah Teori Belajar dan Mengajar Khusus Terhadap Sikap Mengenai Jabatan Guru pada Mahasiswa FPTK. Padang. IKIP Padang.

Amran (1993). Perbedaan Antara Hasil Belajar Mata Kuliah Praktek Mahasiswa PMDK Dengan Mahasiswa PGSD pada Program DII PGSD Penjas IKIP Padang. Padang. IKIP Padang.

Argantos (1989). Pengaruh Metode Mengajar dan Potensi Alat Gerak Tubuh Terhadap Hasil Belajar Renang Mahasiswa PGSD Penjas (Laporan Penelitian) IKIP. Padang.

Arikunto, Suharsimi (2006), Prosedur Penelitian Suatu Pendekatan Praktik. Jakarta : Rineka Cipta.

Arsil. (1999). Pembinaan Kondisi Fisik. Padang : FIK UNP

Asnaldi, A. (2019). Kontribusi Motor Ability Dan Konsentrasi Terhadap Kemampuan Penguasaan Kata Heian Yodan Karateka Lemkari Dojo Angkasa Lanud Padang. Jurnal MensSana, 4(1), 17-29. doi:10.24036/jm.v4i1.30

Harsono (1998). Coaching dan Aspek-aspek Psikologis dalam Coaching.

Lutan, Rusli (1978). Belajar Keterampilan Motorik Pengantar Teori dan Praktek: Depdikbud Dirjen Dikti.

Mulia, A. P., \& Sin, T. H. (2019). Analisis Kondisi Fisik Atlet Sepakbola SMA Negeri 2 Payakumbuh. Jurnal Patriot, 1(01), 94-100. 